\section{Anti-musk positive myasthenia gravis and three semiological cardinal signs}

\author{
André P.C. Matta, 1 \\ Ana C. Andorinho F. Ferreira, \\ Arielle Kirmse, ${ }^{1}$ Anna Carolina Damm, 1 \\ João Gabriel D.I.B. Farinhas, 1 \\ Mariane D. Barbosa, 1 Mayara C.M. Teles, \\ Camila Fiorelli,2 Rossano Fiorelli,2 \\ Osvaldo J.M. Nascimento, 1 \\ Marco Orsini1,3 \\ ${ }^{1}$ Neurology Service, Federal Fluminense \\ University, University Hospital Antônio \\ Pedro, Niterói; 2Medicine School, \\ UNIRIO, RJ; 3Masters Program in \\ Urgency and Medicine Emergency Care \\ USS, Vasssouras, Rio de Janeiro, Brazil
}

\begin{abstract}
Myasthenia gravis (MG) is a relatively uncommon disorder with an annual incidence of approximately 7 to 9 new cases per million. The prevalence is about 70 to 165 per million. The prevalence of the disease has been increasing over the past five decades. This is thought to be due to better recognition of the condition, aging of the population, and the longer life span of affected patients. MG causes weakness, predominantly in bulbar, facial, and extra-ocular muscles, often fluctuating over minutes to weeks, in the absence of wasting, sensory loss, or reflex changes. The picture of fluctuating, asymmetric external ophthalmoplegia with ptosis and weak eye closure is virtually diagnostic of myasthenia. We report an atypical MG case with three semiological cardinal signs.
\end{abstract}

\section{Introduction}

Myasthenia gravis (MG) is a relatively uncommon disorder with an annual incidence of approximately 7 to 9 new cases per million.1,2 The prevalence is about 70 to 165 per million. The prevalence of the disease has been increasing over the past five decade.3,4 This is thought to be due to better recognition of the condition, aging of the population, and the longer life span of affected patients. MG causes weakness, predominantly in bulbar, facial, and extra-ocular muscles, often fluctuating over minutes to weeks, in the absence of wasting, sensory loss, or reflex changes. The picture of fluctuating, asymmetric external ophthalmoplegia with ptosis and weak eye closure is virtually diagnostic of myasthenia.5,6 We report an atypical MG case with three semiological cardinal signs.

\section{Case Report}

A 45-year-old Caucasian man was referred to the Neurology service of our hospital reporting diplopia, dysphagia, dysphonia, and slight limbs weakness that became worse throughout the day for the last seven years. Neurologic examination disclosed palsy of orbicularis oculi muscles configuring the Barré sign (Figure 1A), and paralysis of palate elevation. The examination also showed bilateral peripheral facial palsy and a slight paresis of limbs was noticed, especially in proximal upper limbs. The eltroneuromiography was unremarkable, without significant decrement of abductor digiti minimi muscle motor component of action potential. Even so, it was hypothesized the diagnosis of MG. Therefore, pyridostigmine $60 \mathrm{mg}$ four times a day was prescribed. Despite that, the patient kept complaining of dysphonia and dysphagia. Thus, it was tried the increase of pyridostigmine to 90 mg six times a day. Once there was no improvement a month later, prednisone $80 \mathrm{mg}$ per day, for five days in a row, every seven days, for a period of three months was administered. In the following consultation, it was confirmed the positivity for autoantibodies to muscle-specific tyrosine kinase (MuSK). Videolaringoscopy identified sluggish of soft palate and pillars and diminished abduction of pharyngoepiglottic and ari-epiglottic folds. Thoracic computed tomography was unremarkable.

Since then, the patient has started noticing some improvement of the dysphonia and dysphagia, but the curtain sign and the paresis of orbicularis oculi muscles were maintained. Five months later, he was complaining of nasal regurgitation. Neurologic exam revealed restriction of upward gaze and uvula deviation to the left side: the curtain sign (Figure 1B). The patient also presented depressive mood. Azathioprine $50 \mathrm{mg}$ per day, an increased dose of pyridostigmine (90 $\mathrm{mg}$ three times a day) and fluoxetine $20 \mathrm{mg}$ a day was prescribed. The patient took months to start the preconized dose of azathioprine and did not increase the dose of pyridostigmine. He was oriented to reach the dosage of $100 \mathrm{mg}$ of azathioprine.

We lost his follow-up for three years. At the return, he had suspended pyridostigmine and azathioprine on his own and maintained steroid therapy. He still had complaints of dysphagia e dysphonia. Neurologic examination showed previous findings and trissulcated
Correspondence: André P.C. Matta, Neurology Service, Federal Fluminense University, Hospital Universitário Antônio Pedro, Av. Marques de Paraná 303, 4 andar Prédio anexo, Centro, Niteroi, Rio de Janeiro, Brazil.

E-mail andrepcmatta@hotmail.com

Key words: Neurology; Medicine; Neuromuscular diseases.

Contributions: the authors contributed equally.

Conflict of interest: the authors declare no potential conflict of interest.

Received for publication: 10 December 2015. Accepted for publication: 6 June 2016.

This work is licensed under a Creative Commons Attribution NonCommercial 4.0 License (CC BYNC 4.0).

CC Copyright A.P.C. Matta et al., 2016

Licensee PAGEPress, Italy

Neurology International 2016; 8:6361

doi:10.4081/ni.2016.6361

tongue (Figure 1C). The patient was let only with steroid therapy and Fluoxetine. In the following month, the patient presented the same symptoms but also paresis of extensor cervical muscles. Steroid was increased again to $80 \mathrm{mg}$ a day with a good response.

\section{Discussion and Conclusions}

In this case of anti-MuSK positive MG the authors would like to emphasize the combination of three semiological signs that at least, make this diagnosis possible: Barré sign, trissulcated tongue and curtain sign. The first is marked to combined patterns of weakness of the extra-ocular muscles, levator palpebrae superioris, and orbicularis oculi, and exposure of the eyelashes while the eyes are closed. The second occurs with the presence of three welldefined grooves and the later, characterized by shifting the palate and uvula, showing the involvement of the glossopharyngeal nerve and particularly the vagus nerve, or yet, as in this case, the asymmetrical impairment of the myoneural junction.

Diagnosis of anti-MuSK positive MG obviously depends on the antibody positivity in plasma. 7,8 However, in the presence of these three signs associated to bulbar complaints such as dysphonia and dysphagia, it is imperative to search these rare presentation of MG. A poor response to pyridostigmine, even in high doses, is a crucial finding and should raise suspicion of this rare myasthenic syndrome 


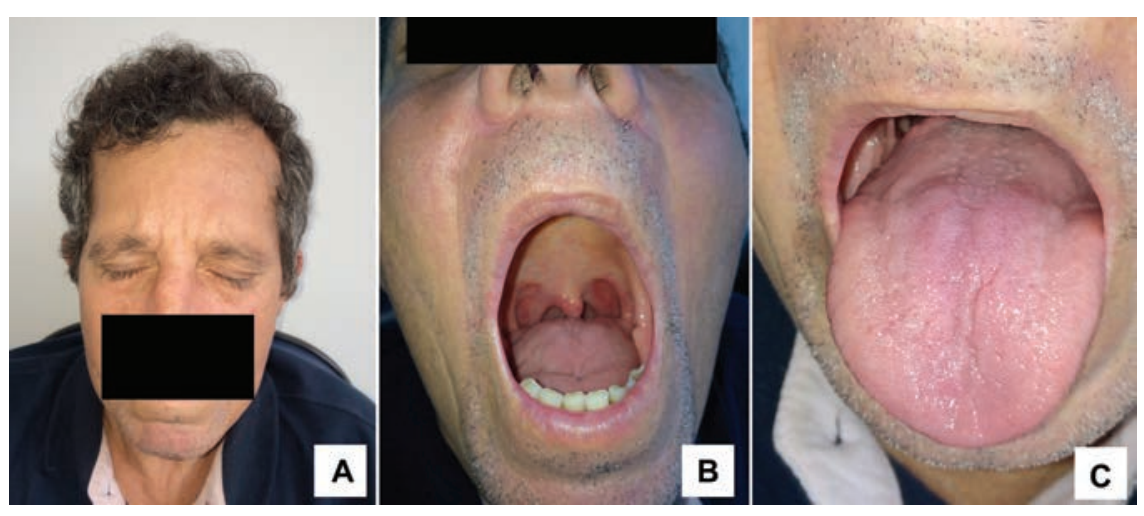

Figure 1. A) Barre sign. B) Curtain sign. C) Trissulcated tongue.

that shows a more reliable improvement with immunosupressor agents. ${ }^{9}$

\section{References}

1. Scherer K, Bedlack R, Simel DL. Does this patient have myasthenia gravis? JAMA 2005;293:1906-14.

2. Dalakas MC. Future perspectives in targetspecific immunotherapies of myasthenia gravis. Ther Adv Neurol Disord 2015;8:31627.

3. Guptill JT, Soni M, Meriggioli MN. Current treatment, emerging translational therapies, and new therapeutic targets for autoimmune myasthenia gravis. Neurotherapeutics 2016;13:118-31.

4. Gilhus NE, Verschuuren JJ. Myasthenia gravis: subgroup classification and therapeutic strategies. Lancet Neurol 2015;14:1023-36.

5. Gwathmey KG, Burns TM. Myasthenia gravis. Semin Neurol 2015;35:327-39.

6. Imai T. Diagnosis, differential diagnosis and laboratory examinations in myasthenia gravis. Nihon Rinsho 2015;73:482-7.

7. Alkhawajah NM, Oger J. Treatment of myasthenia gravis in the aged. Drugs Aging 2015;32:689-97.

8. Oger J, Frykman H. An update on laboratory diagnosis in myasthenia gravis. Clin Chim Acta 2015;449:43-8.

9. Andersen JB, Owe JF, Engeland A, Gilhus NE. Total drug treatment and comorbidity in myasthenia gravis: a population-based cohort study. Eur J Neurol 2014;21:948-55. 